\title{
The Effect of Social Economic Status and Parents' Rearing Behavior on Social Creativity of Children in Mali
}

\author{
Yaya Diarra1, Chuanhua Gu1, Mingchun Guo ${ }^{2}$, Yukang Xue ${ }^{1}$ \\ ${ }^{1}$ Central China Normal University (CCNU) Department of Psychology, Wuhan, China \\ ${ }^{2}$ Department of Psychology, Faculty of Education, Fujian Normal University, Fuzhou, China \\ Email: yayadiarra24@yahoo.fr, guchuanhua@mail.ccnu.edu.cn,mingchun.guo@uq.net.au, xueyukain@qq.com
}

How to cite this paper: Diarra, Y., Gu, C. H., Guo, M. C., \& Xue, Y. K. (2017). The Effect of Social Economic Status and Parents' Rearing Behavior on Social Creativity of Children in Mali. Creative Education, 8, 829846.

https://doi.org/10.4236/ce.2017.86060

Received: March 18, 2017

Accepted: May 16, 2017

Published: May 19, 2017

Copyright $\odot 2017$ by authors and Scientific Research Publishing Inc. This work is licensed under the Creative Commons Attribution International License (CC BY 4.0).

http://creativecommons.org/licenses/by/4.0/

\begin{abstract}
This study investigated the effect of social economic status and parents' rearing behavior on social creativity of children in Mali. Demographic information, social creativity measure, parent behaviors measures were used. The results indicated that: (1) In the social creativity, the difference was not significant between males and females and their parenting behaviors; (2) There had significant differences of scores of social creativity, parenting behaviors among different grades; (3) Social creativity was correlated significantly and positively with home income, parents rearing, and mother's works; (4) Grades and father's rejection could significantly and positively predict children's social creativity. Higher social economic status and parents' rearing behavior help to encourage children's social creativity.
\end{abstract}

\section{Keywords}

Social Economic Status, Social Creativity, Parents ‘Rearing, Children's of Mali

\section{Introduction}

The Creativity could be defined as a set of capacities enabling a person to behave in new and adaptive way in given contexts (Gardner, 1993a; Lautrey \& Lubart, 1998; Lubart, 1994). As Guilford (1968) pointed out, creative behaviour is needed wherever there are problems present, including interpersonal situations. Indeed, as in artistic or scientific fields, a range of social creativity could be observed varying from everyday levels to eminent cases. Unlike Montuori and Purser (Purser \& Montuori, 1999) for whom social creativity applies to the social dimensions of creativity that are involved in each domain of creative occupation, such as its social and historical contexts, they use social creativity to refer to the 
kind of creativity that occurs in the domain of everyday interactions. In addition, they propose that there exists a continuum between interpersonal social creativity and societal social creativity, and that the achievements of some religious or political figures could be seen as major cases of social creativity. Thus, Martin Luther's refusal to recanted his beliefs at the Diet of Worms, which eventually led him to create a new religious movement, or the lifelong political actions of the Indian leader Gandhi (Gardner, 1993a) can be seen as instances of eminent-level creativity in the social domain. At a more everyday level, social creativity might be seen as contributing favourably to interpersonal problem solving as well as leadership, ego formation, self-actualisation, and psychological health.

They expect that this creative capacity will develop as most abilities, and that older children will achieve better than younger ones. Older children are supposed to have access to more efficient search processes than younger ones and have more social experience, allow them to propose more solutions to social problems. A more varied and richer experience in social interaction should also add to a pattern of performance in which older children give more original answers than younger ones. Yet a decrease with age in performance in the social area cannot be totally ruled out, due to the progress of social inhibition, observable in the gradual decline of tolerance for failure in school-aged children (Clifford, 1988).

Creativity results from relations among a variable that could be prepared into cognitive, personality, emotional, and environmental domains (Lubart, Mouchiroud, Tordjman, \& Zenasni, 2003). They measured different types of cognitive, socio-affective as well as environmental variables, and they examine the share variance of each measure with creative performance in social tasks. The emergence of novel ways to resolve social problems or organize social groups has played a key role in social and cultural change. At the individual height, difference in this ability has long been recognized, under various labels. One linked concept is the ancient Greeks' metis, which in broad conditions refers to ingeniousness and wisdom in solving practical problems. According to Destienne and Vernant (1974), this human aptitude has been for 10 centuries a central aspect since Ancient Greece, as personified in Ulysses' cunning character or in works of Greek philosopher and politicians.

Other closely connected construct to social creativity are Ribot's (1906) concept of moral or utopian thoughts in his typology of creative domains (see Mouchiroud \& Lubart, 2006), or Gardner's interindividual intelligence in his Multiple Intelligences theory $(1983,1993)$. Furthermore, the creative nature of social growth has long been documented, in Piaget's (1932) early work on moral development, or later in Spivack and Shure (1974) and Dodge's (1986) creative social difficulty solving perspective. Historical social creativity could also be examined through empirical means, following for instance Simonton's retrospective approach (1997).

The creativity varies from one individual to another and from one domain of expression to another within the same individual (Lubart et al., 2003). The link 
between social creativity and emotion may be even more complex than its relation with personality. In the social creative process, both positives and negative effects can in turn influence the result of social interactions. For example, negative effects associated with feelings of empathy may be involved in raising social problems to conscious levels, or positive emotions such as joy or surprise may help the person persevere in building creative solutions. Negative emotion could also incite uncreative social interactions, because negative emotions may reduce or activate exact sets of behaviors, some attached to aggressive scripts. When confronted with a social conflict, individuals may vary in the way emotions spread into their current memory script, sometimes leading to the activation of specific violence-oriented scripts (Berkowitz, 1984).

Social creativity, in contrast, is a higher-level and extra comprehensive characteristic, comprise the personality tendency for dealing with all sorts of interpersonal relationship and social problems, and cognitive ability. In the past 10 years, researchers have conducted some initial studies on the development of children's social creativity and its relationship with individual, family, school, and peer factor (Mouchiroud \& Lubart, 2002; Mouchiroud \& Bernoussi, 2008; Gu, 2007, 2009; Gu, Huang, \& Zhou, 2008; Gu, Zhang, \& Zhou, 2009). Other studies have explored the development of social leaders' creative personality over the lifespan (Gu, 2011).

\subsection{Environmental Factors of Social Creativity}

Since the mid-twentieth century, the most popular way of classifying investigate on creativity has been the 4 Ps: person, process, pressure, and product (Runco, $1997,2004)$. In other words, creativity research has generally focused on how individual and environmental factor such as personality and working conditions affect the development of creativity (Feldman, 1999).

The prevalence of environmental factor in the likelihood of creative behaviors' is essential. This should be even more true for socially creative behaviors', which by definition occur in a social context. Since (as well as before) birth, the physical and social environment participates in the cognitive, social and emotional development of the child, interactions with the social environment may promote or hinder socially creative development. Family variable such as rank-order, SES, and caretaker' educational method are all potential factor influencing social creativity. Concerning birth-order, later-borns may be more disposed to this form of creative expression. Contrary to firstborns, later-borns be likely to experience more interaction with sibling during their developmental years; this difference might provide them with more opportunities to negotiate and behave creatively. Negotiation activities might also stem from the unbalanced physical relationship between siblings, later-borns being driven early on to verbal instead of physical arguments in conflicts. Biographical data analyse performed on adults by Sulloway (1999) indicate that first-borns are over-represented in occupations such as physical science, whereas later-borns are more often seen in social science or politics. 
Past and present physical and social environments obviously explain significant portions of individual difference in social creativity. Even though individual factors traditionally get more attentions than environmental ones in the field of psychology, some studies have shed light on the role of the child-environment interaction in the development of creative abilities. As an immediate setting, the child's birth rank in the family has been put forward as an important variable for creativity by Sulloway (Sulloway, 1996) who showed that first-borns adults are over-represented in occupation such as physical science, but later-borns are more often seen in social science or politics. Data on personality dimensions corroborate this finding, as later borns rate higher on such as sociability and openness to experience, (two key elements in the socially creative personality), whereas first borns usually place higher emphasis on conformity. According to Sulloway, first birth position, because it includes an environmentally richer developmental phase as the sole childs in the family, should favor the development of the type of cognitive skill measured in classical IQ tests. In contrast, later borns have to-share their parents with their older sibling from the very first day, which restricts their interactions with them. Alternatively, later borns should experience more interaction with sibling during their developmental years, providing them with more opportunities to negotiate and thus acquire experience in the social activities.

\subsection{Link between Parenting Style and Creativity}

The permissive parent behaves in a nonpunitive, accepting and affirmatives manner towards the child's impulses, desires and actions. These parents also consult with the child about decisions and explain family rules with few demands being made on the child for household, responsibility and orderly behavior. The child allows to regulate her or his own activities and is not encouraged to obey externally defined standards (Baumrind, 1966). The authoritarian parents is one who shape, controls and evaluate the behavior and attitude of the child in accordance with a set normal of conduct. These standards are frequently complete, theologically motivated and formulate by a higher authority. Submission is valued and punitive, forceful measures are use to curb the children behavior. The children autonomy is restricted, household responsibilities are used to inculcate respect, and a sense of work and order is valued and preserve. The child is not consulted on issues, and the parent's word is frequently (Baumrind, 1966). The authoritative parents, on the other hand, direct the child's activitie but in a normal, issue-oriented way. The child is encouraged to participate verbally, policies are explained and where there are objection from the child, these objection are discussed. Autonomy, self will, and discipline, conformity are valued. Though confirm if the control is exerted, the child is not restricted, and the child's individual interest are recognized and valued (Baumrind, 1966). Cropley (1967) purported, that a relationship exists between creativity and parenting style. Specifically, it was emphasized that parent of creative kids were found to encourage personal autonomy and independence and were less concerned with 
right or conventional behaviors.

According to Torrance (1969), creative thinking is a process, and all through this process is an element of respond constructively to existing or new situations rather than merely adapting to them. This definition seeks to place creativity in the realm of every days life and does not reserved it for ethereal and rarely achieve heights of creation (Torrance, 1969). One significant factor that has been shown to influence creativity is that of the family and the family environment. Torrance (1965) alluded to the importance of the family environment and the role of parents in fostering on creativity. He posited that if children are to develop creatively then parents must value those personality distinctiveness that will ensure the development of theirs creative potential. Torrance (1965) more pointed out that characteristics such as stubbornness, independent thinking, possibility taking, originality and sensitivity characterized the creative individual.

\subsection{Social Economic Status}

The Socioeconomic status (SES) is an economic and sociological combined total measure of a person's work knowledge and of an individual or family's economic and social position in relation to others, based on income, education, and occupation. When analyze a family's SES, the household income, earners' education, and occupation are examine, as well as combine income, versus with an individual, when their own attribute are assessed. Or further commonly know to depict an economic difference in society as a whole (case and colleagues 2002).

Research focused on family environment and cognitive development emphasize the relationship between style and family's socio-economical status (Lautrey, 1980). This macro variable also affects the child's proximate social environment beyond the family circle. For example, children from higher status families are further likely to participate in extra-curricular activities, which in turn are believed to impact the development of creativity (Milgram \& Hong, 1999).

Another variable partly linked with SES is school environment. Schools can indeed vary significantly in terms of providing children with environments that allow democratic decisions, such as the ones proposed in alternative educational programs (see for example Clandfield \& Sivell, 1990), as well as the presence or absence of a mentor (Torrance, 1981). Besides the immediate environment, social creativity may also depend on more global variable, such as broad economical and societal context (see Lubart et al., 2003).

The socioeconomic background impacts adolescent, development, particularly their creative capability and creativity-related personality traits. It is well establishe that there is an academic achievement gap between students from high and low socioeconomic family background (Byrnes, 2003; Frederickson \& Petrides, 2008; McLoyd, 1998; Murdock, 2000). Multiple factors, mechanisms, and pathway through which low SES puts student at risk for academic failure have also been researched in depth (Grissmer, Williamson, Kirby, \& Berends, 1998). They involve, among others, parental supervision, material resources, and intellectual 
stimulation and value. The question of a possible creativity gap between high and low socioeconomic status (SES) or, more broadly, of social and educational underpinnings of SES underlying the development of creative potential, has not been brought up and well addressed.

However In this study we focus only on the effect of the social economic status and parents' rearing behavior on the social creativity of children in Mali. For future research we should take into explanation the influence of teachers, the environment (family, peers, gender) factor cognitive, the personality of the children, his rank in the family, all of whom are involved in his social creativity. Because the creativity result from interactions among variable, that can be organize into cognitive, personality, emotional, and environmental domains (Lubart, Mouchiroud, Tordjman, \& Zenasni, 2003).

\section{Methods}

\subsection{Participants}

The researcher's population was pre-defined since the research theme necessitated the participation of participant in the study will all be middle school they are aged 9, 10, 11 years. Focus on 4e degree, 5e degree, 6e degree totaled at 262 children's in my country. In $4 \mathrm{e}$ degree there are 82 children's 30 boys and 52 girls, in 5e degree 90 children's 28 boys and 62 girls, in 6e degree 90 Children's 41 boys and 49 girls. They have been selected from two primary schools.

All our participants live in the city they are all in public schools. The living conditions of the families are different according to the socioeconomic status of the families. There are more girls than boys in different degrees this is explained by the fact that the government now promotes the schooling of the girl in all schools, because previously the rate of schooling of the girl was very low compared to that of the boy.

\subsection{Measurements}

The questions in the questionnaire will target information in four sections. 1-demographic information, 2-questionnaire-Social creativity measure, 3 questionnaire-parent behaviors.

\subsection{Demographic Information}

In this part I told about a family relationship (What is the relationship between, the number of people who live in the room, the numbers of siblings. Occupation of parents (father's job, mother's job) home income, parent's education.

\subsection{Social Creativity Measure Questionnaire}

Open-ended question about social difficulty situations Adolescents' social creativity was assessed using open-ended questions about social problem situations. Firstly, the high school students were interviewed about their daily life asking them open-ended questions about the kinds of social problems they commonly encountered. The typical social problems they faced were identified accordingly. 
Finally, the open-ended question about social problem situation were compiled using the relevant research (Gu, Liu, \& Zhou, 2010) as a reference, including six typical situations concerning time management, emotion regulation, learning, establishing interpersonal relationships, heterosexual relationships and peer relationships. Every situation was presented as a story, and the adolescent were asked to provide as several solutions as possible to help the character to resolve the problem. The participants could answer the question in any order, regardless of the sequence of the six situations, and their responses were given anonymously.

Taking relevant research $(\mathrm{Gu}, 2009,2011)$ as a reference, five dimensionsoriginality, fluency, flexibility, appropriateness, and utility-were measured. Originality is the extent to which a solution differs from others; appropriateness is the extent to which a solution is acceptable to society; utility is the level to which the solution solves the problem; flexibility refers to the number of categories of solutions; and fluency refers to the fluency of the participant's thinking.

The participants were asked to respond independently and indicate their attitude to the adolescents social Creativity task (voluntary or reluctant) after answering the question "Are you interested in answering these questions?" by selecting either "Yes" or "No, but I will answer them for the sake of completing the task" ("Yes" representing voluntary, "No" representing reluctant). Hence, the study used a 2 (willingness to complete the task: reluctant, voluntary) 93 (general creative personality: high, medium, low) experimental design. The freedom of task choice referred to whether the participant was willing to accept and complete, the task in the current study. The voluntary participants completed the task without feeling forced, due to its intrinsic interest. In contrast, those who completed it reluctantly did so for external reasons rather than intrinsic interest. It can be used to investigate the social creativity of children.

\subsection{Parenting Behavior Scale (S-Embu)}

This questionnaire was developed by Arrindell, Sanavio, Aguilar, et al. (1999). It includes three dimensions:

Out of the necessity of having an abbreviate form of the EMBUla measure of perceived parental rearing behavior, a short form EMBU consisting of three scales "Rejection\Emotional Warmth and Protection, with respectively $7 \backslash 6$ and 9 items "plus 1 unscaled item was developed from the original 81 item version.

The present study specifically sought to (a) select an item pool for a short EMBU "henceforth EMBU based on item! Content and on previous psychometric analyses (b) examine the factorial validity and reliability of the! EMBU taking into account the factor structure of the early EMBU "Arrindell +van der Ende (c) provide evidence of construct validity by relating there sulting factorially! Derived dimensions of the EMBU to major Eysenckian dimensions of personalitylsex role orientation and self! Esteem "predictions as outlined below.

For selecting items for the short form First the items has to be with those that loade at least highly on the Rejection Emotional Warmth or Protection factors 
before identified among the early EMBU as being invariant across a large number of nation, and which did not result in appreciable reduction of internal consistencies if remove from their theoretically relevant scales Arrindell et al. Use this criterion led to the removal of the favoring subject factors which in some countries had emerged as unstable and: or unreliable, Second item selection was done in such a way that it would result in measures that sample the different elements that are reflected by a specific construct, yet still measure that specific construct in an internally consistent fashion the bandwidth versus fidelity issue in measurement reliability The following element were deemed relevant "compare Arrindell Gerlsma Vandereycken Hageman Daeseleire for Rejection punitive, shaming, favoring siblings over the rejection through criticism rejection of the $S$ as an individual and abusive for Emotional Warmth affectionate stimulating and praising for Protection fearful and anxious for safety intrusive over involved In following these criteria 6, 5 and 09 items were chosen for the Rejection Emotional Warmth and Protection factors respectively thereby reducing the original 70 ! Item form to one of 12 items.

\subsection{Procedure}

For the participants the questionnaire were administered in the following sequence The time permitted for each questionnaire is 40 minutes, this time is sufficient for all of the children to complete the task.

\section{Results}

\subsection{The Score of Children of Boys and Girls on Social Creativity and Parenting Behavior in Mali}

Table 1 showed the means and standard deviations the scores of boys and girls on the social creativity. Table 1 The descriptive statistics and t-test of children, boys and girls on social creativity and parenting behavior.

Table 1 provides the means and standard deviations for the scores of students of different gender. As can be seen from Table 1, the results show, that the social

Table 1. Gender differences.

\begin{tabular}{cccc}
\hline & Male & Female & $t$ \\
& M \pm SD & M \pm SD & \\
Social creativity & $22.34 \pm 3.02$ & $22.37 \pm 3.69$ & -0.073 \\
Father emotional warmth & $15.77 \pm 3.03$ & $15.40 \pm 2.85$ & 1.01 \\
Father rejection & $15.71 \pm 3.41$ & $15.14 \pm 3.25$ & 1.37 \\
Father protection & $23.81 \pm 5.85$ & $23.18 \pm 5.54$ & 0.91 \\
Mother emotional warmth & $16.20 \pm 2.75$ & $15.81 \pm 2.74$ & 1.12 \\
Mother rejection & $16.24 \pm 2.92$ & $15.62 \pm 3.09$ & 1.61 \\
Mother protection & $24.75 \pm 4.85$ & $24.00 \pm 5.52$ & 1.13 \\
\hline
\end{tabular}

${ }^{*} \mathrm{P}<0.05,{ }^{* *} \mathrm{P}<0.01,{ }^{* * *} \mathrm{P}<0.001$. 
Table 2. Grades differences.

\begin{tabular}{|c|c|c|c|c|}
\hline & \multicolumn{3}{|c|}{ Grades } & \multirow{3}{*}{$F$} \\
\hline & 4 & 5 & 6 & \\
\hline & $\mathrm{M} \pm \mathrm{SD}$ & $\mathrm{M} \pm \mathrm{SD}$ & $\mathrm{M} \pm \mathrm{SD}$ & \\
\hline Social creativity & $21.08 \pm 4.02$ & $22.54 \pm 3.41$ & $23.32 \pm 2.43$ & $10.03^{* * *}$ \\
\hline Father emotional warmth & $14.75 \pm 2.62$ & $16.02 \pm 3.35$ & $15.78 \pm 2.60$ & $4.62^{\star}$ \\
\hline Father rejection & $13.85 \pm 3.48$ & $14.82 \pm 2.98$ & $17.26 \pm 2.52$ & $30.25^{* * *}$ \\
\hline Father protection & $20.66 \pm 5.23$ & $22.39 \pm 4.77$ & $26.97 \pm 4.56$ & $40.10^{* * *}$ \\
\hline Mother emotional warmth & $15.19 \pm 2.26$ & $16.44 \pm 3.03$ & $16.18 \pm 2.71$ & $5.14^{\star *}$ \\
\hline Mother rejection & $14.83 \pm 3.22$ & $15.03 \pm 2.86$ & $17.63 \pm 2.13$ & $28.81^{* * *}$ \\
\hline Mother protection & $22.30 \pm 5.33$ & $22.65 \pm 4.63$ & $27.72 \pm 4.01$ & $38.18^{\star * *}$ \\
\hline
\end{tabular}

${ }^{*} \mathrm{P}<0.05,{ }^{* *} \mathrm{P}<0.01,{ }^{* * *} \mathrm{P}<0.001$.

creativity of males $(M=22.33$, S.D $=302)$ was higher than the social creativity of females, $(M=22.36, S D=3.08)$. However the difference was not significant $(t=$ $-0.073, \mathrm{p}>0.05)$. And for males and females, there were no significant difference between their parents' parenting styles.

\subsection{The Score of Children of Different Grades on Social Creativity and Parenting Behavior in Mali}

Table 2 showed the scores of social creativity and parenting style (father emotional warmth, father rejection, father protection, mother emotional warmth, mother rejection, mother protection) among different grades $\left(4^{\text {th }}, 5^{\text {th }}, 6^{\text {th }}\right)$.

Table 2 The descriptive statistics and F-test of children of different grades on social creativity and parenting behavior.

From Table 2 we could see that there are significant differences of scores of social creativity, father emotional warmth, father rejection, father protection, mother emotional warmth, mother rejection, and mother protection among different grades.

Main effect of grades on social creativity was significantly, $\mathrm{F}=10.03, \mathrm{p}<$ 0.001. Post hoc results showed that $4^{\text {th }}$ grades had significant lower scores than $5^{\text {th }}$ grades (Mean difference $\left.=-1.46, \mathrm{p}<0.05\right)$ and, $4^{\text {th }}$ grades also had significant than $6^{\text {th }}$ grades (Mean difference $=-2.23, \mathrm{p}<0.001$ ).

Main effect of grades on father emotional warmth was significant, $\mathrm{F}=4.62, \mathrm{p}$ $<0.05$. Post hoc results showed that $4^{\text {th }}$ grades had significant lower scores than $5^{\text {th }}$ grades (Mean difference $=-1.26, \mathrm{p}<0.05$ ).

Main effect of grades on father rejection was significant, $\mathrm{F}=30.25, \mathrm{p}<0.01$. Post hoc results showed that $4^{\text {th }}$ grades had significant lower scores than $6^{\text {th }}$ (Mean difference $=3.41, \mathrm{p}<0.001)$ and $5^{\text {th }}$ also had significant than $6^{\text {th }}$ grades (Mean difference $=-2.43, \mathrm{p}<0.001$ ).

Main effect of grades on father protection was significant, $\mathrm{F}=40.10, \mathrm{p}<0.01$. Post hoc results showed that $4^{\text {th }}$ grades had significant lower scores t han $6^{\text {th }}$ (Mean difference $=-6.30, \mathrm{p}<0.001)$ and $5^{\text {th }}$ also had significant than $6^{\text {th }}$ grades 
(Mean difference $=-4.58, \mathrm{p}<0.001$ ).

Main effect of grades on mother emotional warmth was significant, $\mathrm{F}=5.14, \mathrm{p}$ $<0.05$. Post hoc results showed that $4^{\text {th }}$ grades had significant lower scores than $5^{\text {th }}$ (Mean difference $\left.=-1.25, \mathrm{p}<0.01\right)$ and $4^{\text {th }}$ also had significant than $6^{\text {th }}$ grades (Mean difference $=-0.99, \mathrm{p}<0.05$ ).

Main effect of grades on mother rejection was significant, $\mathrm{F}=28.81, \mathrm{p}<0.001$. Post hoc results showed that $4^{\text {th }}$ grades had significant lower scores than $6^{\text {th }}$ (Mean difference $=-2.80, \mathrm{p}<0.001$ ) and $5^{\text {th }}$ also had significant than $6^{\text {th }}$ grades (Mean difference $=-2.60, \mathrm{p}<0.001$ ).

Main effect of grades on mother protection was significant $\mathrm{F}=38.18, \mathrm{p}<$ 0.001 . Post hoc results showed that $4^{\text {th }}$ grades had significant lower scores $6^{\text {th }}$ (Mean difference $=-0.35, \mathrm{p}<0.001$ ) and $5^{\text {th }}$ also had significant than $6^{\text {th }}$ grades (Mean difference $=-5.08, \mathrm{p}<0.001)$.

\subsection{The Correlation between Social Creativity of Children and Their Socio Economic Status and Parents' Rearing Behavior}

Table 3 showed the correlation between different variables including home income, father education, mother education, father emotional warmth, father rejection, father protection, mother emotional warmth, mother rejection, mother protection, father work's, mother work's, social creativity of children in Mali.

Table 3 Correlations between social creativity of children and their socio economic status and parents' rearing behavior.

This table showed the correlation among different variables.

Mother education was significantly correlated and positively with home income and father education. Father rejection was a significantly positively corre-

Table 3. Correlations.

\begin{tabular}{|c|c|c|c|c|c|c|c|c|c|c|c|c|}
\hline Variables & 1 & 2 & 3 & 4 & 5 & 6 & 7 & 8 & 9 & 10 & 11 & $12 q$ \\
\hline 1 Ho inc & 1 & & & & & & & & & & & \\
\hline 2 Fat Ed & $0.482^{* *}$ & 1 & & & & & & & & & & \\
\hline 3 Mot Ed & $0.626^{\star *}$ & $0.577^{\star *}$ & 1 & & & & & & & & & \\
\hline $4 \mathrm{Fa} \mathrm{E} \mathrm{W}$ & 0.064 & 0.022 & 0.003 & 1 & & & & & & & & \\
\hline 5 Fat $\operatorname{Re}$ & $0.162^{\star *}$ & $0.206^{* *}$ & 0.117 & $0.342^{* *}$ & 1 & & & & & & & \\
\hline 6 Fat Pr & $0.163^{* *}$ & $0.150^{*}$ & 0.083 & $0.402^{\star *}$ & $0.772^{* *}$ & 1 & & & & & & \\
\hline 7 Mo E W & 0.038 & 0.031 & -0.010 & $0.760^{* *}$ & $0.325^{* *}$ & $0.362^{* *}$ & 1 & & & & & \\
\hline 8 Mot $\operatorname{Re}$ & $0.174^{* *}$ & $0.280^{* *}$ & $0.179^{* *}$ & $0.139^{*}$ & $0.753^{* *}$ & $0.632^{\star *}$ & $0.215^{* *}$ & 1 & & & & \\
\hline 9 Mot $\operatorname{Pr}$ & $0.142^{*}$ & $0.122^{*}$ & 0.076 & $0.279^{* *}$ & $0.705^{\star *}$ & $0.865^{\star *}$ & $0.314^{\star *}$ & $0.701^{\star *}$ & 1 & & & \\
\hline 10 Fat Wk & $0.446^{* *}$ & $0.140^{*}$ & 0.031 & 0.004 & -0.016 & 0.004 & 0.024 & -0.060 & 0.005 & 1 & & \\
\hline 11 Mo wk & $0.811^{\star *}$ & $0.323^{\star *}$ & $0.523^{\star *}$ & $0.037 \mathrm{e}$ & $0.165^{\star *}$ & $0.194^{\star *}$ & 0.005 & $0.175^{\star *}$ & $196^{* *}$ & 0.094 & 1 & \\
\hline 12 So Cre & $0.121^{\star}$ & 0.130 & 0.077 & $0.218^{* *}$ & $0.363^{* *}$ & $0.347^{* *}$ & $0.161^{* *}$ & $0.233^{* *}$ & $0.297^{* *}$ & -0.062 & $0.168^{* *}$ & 1 \\
\hline
\end{tabular}

${ }^{*}$ Correlation is significant at the 0.05 level $\left(2\right.$-tailed). ${ }^{*}$ Correlation is significant at the 0.01 level $(2$-tailed). $1=$ Home income, $2=$ Father education, $3=$ Mother education, $4=$ Father emotional warmth, $5=$ Father rejection, $6=$ Father protection, $7=$ Mother emotional warmth, $8=$ Mother rejection, $9=$ Mother protection, $10=$ Father work's yes \& no, $11=$ Mother work's yes $\&$ no, $12=$ Social creativity. 
lated with home income father education, and father emotional warmth, father protection.

There was a significant and positive correlation between mother rejection and home income, father education, mother education, father emotional warmth, father rejection, father protection, mother emotional warmth, and mother rejection too.

Mother's work yes or no was significantly and positively correlated with home income, there was significantly and positively correlated with father education, mother education, father rejection, father protection, mother rejection, and mother protection.

Social creativity was correlated significantly and positively with home income, there was also a significant and positive correlation between social creativity and father emotional warmth, father rejection, father protection, mother emotional warmth, mother rejection, mother protection, and mother work's yes or no

\subsection{The Regression of Social Creativity of Children on Their Social Economic Status and Parents' Rearing Behavior}

To analyze the effect of children's socioeconomic status and their parents' rearing behavior on their social creativity, the Hierarchical Multiple regression analysis was conducted. The results were as follows. Table 4 showed parents rearing, home income, education and works of parents on the social creativity of children.

Table 4 The regression of social creativity of children on their socioeconomic status and parents' rearing behavior.

Table 4. Hierarchical regression.

\begin{tabular}{|c|c|c|c|c|c|c|c|c|c|}
\hline \multirow{2}{*}{ variables } & \multicolumn{3}{|c|}{ First Hierarchical } & \multicolumn{3}{|c|}{ Second Hierarchical } & \multicolumn{3}{|c|}{ Third Hierarchical } \\
\hline & B & $\mathrm{t}$ & $\mathbf{P}$ & B & $\mathrm{t}$ & $\mathrm{p}$ & $\beta$ & $\mathrm{t}$ & $\mathbf{P}$ \\
\hline Gender & -0.009 & -0.158 & 0.857 & -0.008 & -0.138 & 0.870 & -0.026 & -0.45 & 0.635 \\
\hline Grades & 0.262 & $4.43^{* * *}$ & 0.000 & 0.234 & $390^{* * *}$ & 0.000 & 0.117 & 1.80 & 0.079 \\
\hline Home income & & & & 0.030 & 0.188 & 0.837 & 0.017 & 0.11 & 0.908 \\
\hline Father education & & & & 0.114 & 1.525 & 0.101 & 0.091 & 1.23 & 0.188 \\
\hline Father'sWork & & & & -1.088 & -1.114 & 0.232 & -0.092 & -1.12 & 0.250 \\
\hline Mother education & & & & -0.092 & -1.037 & 0.262 & -0.061 & -0.71 & 0.440 \\
\hline Mother's work & & & & 0.124 & 1.024 & 0.311 & 0.097 & 0.81 & 0.418 \\
\hline Father emotional warmth & & & & & & & 0.115 & 1.24 & 0.192 \\
\hline Father rejection & & & & & & & 0.279 & $2.58^{\star}$ & 0.009 \\
\hline Father protection & & & & & & & 0.059 & 0.43 & 0.657 \\
\hline Mother emotional warmth & & & & & & & -0.049 & -0.55 & 0.552 \\
\hline Mother rejection & & & & & & & -0.143 & -0.15 & 0.154 \\
\hline Mother protection & & & & & & & 0.057 & 0.44 & 0.682 \\
\hline $\mathbf{R}^{2}$ & & 0.068 & & & 0.100 & & & 0.168 & \\
\hline$\Delta \mathrm{R}^{2}$ & & & & & 0.032 & & & $0.086^{* * *}$ & \\
\hline
\end{tabular}


In this table From the Hierarchical regression we could see that grades and father's rejection can significantly and positively predict children's social creativity.

\section{Discussion}

\subsection{The Score of Social Creativity and Parenting Behavior of Boys and Girls in Mali}

In this study we found that, in Mali, there were no a significant difference between boys and girls on social creativity and parenting behavior of children. The score of social creativity of boys was higher than of the score of girls but the difference was not significant. Research on creativity has shown that boys and girls vary on different, measures of divergent thinking. Boys tend to score higher on logical measures, where as girls score higher on verbal ones; the differences were only marginal. The analysis of boys and girls separately may help to give a better understanding of the pattern of creativity development, Lubart (2008).

In Mali the boys are freer than girls to do many things. After school the boys can play with their friends (football games etc) however, some time girls need to help their mothers to do the household work and they don't have much time to play with their friends. The social creativity will be higher if the child facing the social situation to solve. In our culture, parents' attitudes girls and boys was not the same (the boys are more free than girls). This factor could explain the different score between boys and girls on the social creativity and parenting behaviors in Mali.

\subsection{The Score of Children of Different Grades on Social Creativity and Parenting Behavior in Mali}

In this study we found that there are significant differences between different grades on social creativity and parenting behavior of children in Mali. Social creativity, father rejection, father protection, mother rejection, mother protection is positively significant. $4^{\text {th }}$ grades had significantly lower scores than $5^{\text {th }}$ grades and, $5^{\text {th }}$ grades also had significantly than $6^{\text {th }}$ grades. The creative capacity will develop as most abilities, and older children will perform better than younger ones. The creativity capacity will develop as most abilities, and that older children will perform better than younger ones, Older children have access to more efficient search processes than younger ones and have more social experience, allowing them to propose more solutions to social problems. A more diverse and richer experience in social interaction contribute to a pattern of performance in which older children give more original answers than younger ones, Clifford (1988).

In our culture the social creativity of each ages are different, the old children are facing more problems and situation than the younger and then using more of their social creativity to find some solutions than younger, this factor could explain why progressively the level of grades are bid the social creativity is higher. 
Results from these studies served to prove the first hypothesis. The results showed that there were statistically significant differences in grade gender on social creativity, socio economic status and parents rearing behavior of children in Mali.

\subsection{The Correlation between Social Creativity of Children and Their Socioeconomic Status and Parents' Rearing Behavior}

In this study we found that the social creativity was correlated significantly and positively with home income, there was also a significant and positive correlation between social creativity and father emotional warmth, father rejection, father protection, mother emotional warmth, mother rejection, mother protection, mother work's (yes or no) and father work's (yes or no).

Father education, mother education, father work's (yes or no), mother work's (yes or no), correlated significantly and positively with home income.

The development of creativity in children was studied by Miller and Gerard (1979). This review highlighted a variety of parenting factors, including parenting styles that influence creativity. Specifically the review pointed out that creative children have parents who treat them with respect, have confidence in their abilities, and give them responsibility with autonomy and freedom, and expect them to do well. This speaks to the authoritative style of parenting. However the review further found that children's creativity tends to be lower in families where parent-child relations are characterize by overt hostility, rejection, and detachment. Lower economic status, has been shown to negatively influence the emotional resource of the parent leading to less responsive, added punitive parenting. In turn, children are often negatively affected and are less likely to succeed in school and have a positive relationship with the parent. However, in some case, families living in unsafe neighborhood had a more positive connection with family member as they pulled together to focus on safety. The authoritative parenting style is more widely employed among parents with higher SES, resulting in a more responsive, more positive relationship with their children. Access to after school and educational income encourage more discussion between parent and child when considering which activities' to pursue. In the long term, this benefits the child by strengthening self-awareness and autonomy. Authoritative parenting lead to clear opportunity of the child and this correlates with findings in higher SES families, particularly regarding school success. (Deborah Stambler, 2008).

It is a well known fact that substantial differences exist in the child rearing patterns at various socioeconomic levels. Children from lower socioeconomic situations are often forced to engage in autonomous behavior earlier than children from middle socioeconomic circumstances (Harry A Little 1961).

The socioeconomic status is very important for the social creativity of children. In my country the social creativity is more determinate by the socioeconomic status; for the children whose parents are educated and have a good job, their social creativity is greater than that of the child whose parents aren't edu- 
cated and don't have à job. The child's whose parents have socioeconomic status and resources could have a lot of games, the time for playing with his peers, parents' attentions and the freedom for many things. All these factors develop his social creativity. It's the opposite for children whose parents haven't a socioeconomic status; sometimes you will find their parents aren't educated and don't have a job. They have neither money for their children scholarship no enough income to take care of all the members of their family. In these conditions the children will not go to the school or have the time for playing with his peers. Thus his social creativity will not be as high as the child's who parents' socioeconomic statuses are higher.

\subsection{The Regression of Social Creativity of Children on Their Socio Economic Status and Parents' Rearing Behavior}

In this study we found that grades and father's rejection can significantly and positively predict children's social creativity. $\mathrm{Gu}$, Chen, $\mathrm{Xu}$, (2003) found that creative political leaders tended to had stern fathers and warm mothers during childhood, which might mean that fathers' sternness or rejection may encourage some children with unyielding character to try their best to interact with others, solve their social problems in their life independently, and form best relationships with others except fathers. This will further help to develop their social creativity.

In our culture, we learn very early to be independent of them parents and find ourselves the solutions to various problems and situations. This is not a rejection but it is their philosophy. They want to teach us values such as independence, responsibility etc. Children who were educated in that direction quickly learn to deal with different problems of their environment and their finding solutions and that will develop his social creativity.

Authoritative parenting has been associated with positive outcomes in North American children and adolescents such as high academic achievement and psycho social competence and low adjustment problems, whereas the opposite relations have been found for authoritarian parenting (Baumrind, 1996; Maccoby \& Martin, 1983).

In Mali the child is in contacts more with his mother and his peers than his father. The father is often absent from the family, so the major part of the education of the child is going with his mother's brothers and sisters. This phenomenon cannot be explained by the paternal rejection; it is a cultural phenomenon that is part of our education. The child who was educated in this direction will be faced with the situations of his environment that he will be creative and try to find solutions to and be enlightened. The results showed that Socio economic status and parents' rearing behavior have significant effects on social creativity of children in Mali.

\section{Conclusion}

In conclusion, relevant conclusions about what has been found in this study are 
highlighted. Finally, it ends with a number of recommendations for action and future research.

In conclusion, it can be said that in the social creativity of boys was higher than the girls, but there are no significant differences between boys and girls and their parents' parenting styles.

In our study, there were significant differences of scores of social creativity, father emotional warmth, father rejection, father protection, mother emotional warmth, mother rejection, and mother protection among different grades. However, there were differences between different grades on social creativity and parenting behavior of children in Mali. The $4^{\text {th }}$ grades had significantly lower scores than $5^{\text {th }}$ grades and, 5thgrades also had more significance than $6^{\text {th }}$ grades.

The social creativity of children was significantly determined by home income, and there were a correlation between several variables home income, father emotional warmth, father education father rejection, father protection, mother emotional warmth, mother education, mother rejection, mother protection, mother work's (yes or no) and father work's (yes or no). All of these variables contribute to the social creativity.

In the social creativity of children on their socioeconomic status and parents' rearing behavior we find that the grades and the father rejection can significantly and positively predict the social creativity of children's in Mali.

\section{References}

Baumrind, D. (1966). Effects of Authoritative Parental Control on Child Behavior. Child Development, 37, 887-907. https://doi.org/10.2307/1126611

Dodge, K. A. (1986). A Social Information Processing Model of Social Competence in Children. In M. Perlmutter (Ed.), Minnesota Symposia on Child Psychology (pp. 77-125).

Feldman, D. H. (1999). The Development of Creativity. In R. J. Sternberg (Ed.), Handbook of Creativity (pp. 169-186). New York, NY: Cambridge University Press.

Gu, C., Huang, C., \& Zhou, Z. (2008). The Relationship between Primary School Children's Social Creativity and Social Skills and Its Enlightenment on Education. Educational Research and Experiment, 56-59.

Lubart, T. I., Mouchiroud, C., Tordjman, S., \& Zenasni, F. (2003). Psychology of Creativity. Paris: Armand Colin.

Lautrey, J. (1980). Social Class, Family Environment, Intelligence. Paris: Presses Universitaires de France.

Miller, B. C., \& Gerard, D. (1979). Family Influences on the Development of Creativity in Children: An Integrative Review. Family Coordinator, 295-312.

https://doi.org/10.2307/581942

Mouchiroud, C., \& Lubart, T. I. (2002). Social Creativity: A Cross-Sectional Study of 6-to 10-Year-Old Children. International Journal of Behavioural Development, 60-69. https://doi.org/10.1080/01650250042000591

Mouchiroud, C., \& Lubart, T. I. (2006). Past, Present and Future Perspectives on Creativity in France and French-Speaking Switzerland. In R. J. Sternberg, \& J. C. Kaufman (Eds.), International Handbook of Creativity (pp. 96-123). New York, NY: Cambridge 
University Press. https://doi.org/10.1017/CBO9780511818240.005

Piaget (1932). The Child's Moral Judgment. Paris: PUF.

Simonton, D. K. (1988). Creativity, Leadership, and Chance. In R. J. Sternberg (Ed.), The Nature of Creativity: Contemporary Psychological Perspectives (386-426). New York, NY: Cambridge University Press.

Spivack, G., \& Shure, M. B. (1974). Social Adjustment of Young Children. A Cognitive Approach to Solving Real-Life Problems. San Francisco, CA: Jossey-Bass. 


\section{Appendix}

\section{Part One: Background Information}

Directions: I want to know how you think about conflicts and problems in your life. First, read the situations below. Then, tell me what would you do in the situation? Write as little or as much as you want but please do not spend more than five minutes responding to each situation. Your responses are confidential and will not be shared with your teacher or anyone else at this school. Also, they will not be graded. I want to know your ideas, so please do not talk to anyone else while you write down your ideas. Do, however, feel free to share this information with your parent/guardian.

Please tell us your:

School:

Grade: Homeroom Section: Birth date: Month/ Year)

Who is/are your primary caregiver(s)?

What is this person's relationship to you? This person is my:

— Mother Father Grandparent Other relative (aunt, uncle, brother, sister)

Non-relative

How many siblings (brothers and sisters) do you have?

How many people reside in your home?

How many of these people are relatives? Non-relatives?

Please put an $\mathbf{X}$ in the following circle that describes you.
Gender:
O male
O female

\section{Occupation of parents:}

Father: Job, Yes.... No....

If it's yes what occupation............

Mother: Job, Yes.... No....

If it's yes what occupation............

Home income: A(Poor). B(Very poor). C(satisfactory). D(very satisfactory)

\section{Parents Education:}

Father: Never go to school. B. Primary school...C secondary school...D university......

Mother: Never go to school. B. Primary school...C secondary school...D university.....

\section{Part Two: Social Creativity Measure Questionnaire}

Directions: Please answer the following questions to indicate how much you disagree or agree with each statement. Please put an $\mathrm{X}$ in the box that seems to best describe how you feel about the situation. There are no right or wrong answers. Just indicate your level of agreement or disagreement with the statement. Strongly disagree, Disagree, Agree, Strongly agre.

When I have a conflict with my classmates, I try my best to solve the conflict.

I have my own opinions and I am not afraid of my classmates making fun of 
me.

When I have a conflict with my classmates, I often come up with unique solutions.

When I have a conflict with my classmates, I can come up with many solutions to solve the conflict.

When I have a conflict with my classmates, I try to solve it no matter what.

When I have a conflict with my classmates, I can think about the conflict in many different ways.

When there is a conflict in the classroom, I can come up with solutions that everyone agrees to

When I work with others, I always get my work done.

\section{Part Three: Parenting Behavior Scale}

Directions: For each statement, decide how often you think your parent/ guardian do each of the following. Please put an $\mathbf{X}$ in the box to indicate how often your parent(s)/guardian(s) does/do the behavior described in the statement. Provide a response for each of your parents/guardians. There are no right or wrong answers, Never, Sometimes, Often, Very often.

When my parent/guardian is upset with me, they tell me why.

When I come home, my parent/guardian expects a report about where I was and what I did.

My parent/guardian scolds/fusses at me in front of others.

My parent/guardian does not let me do things other kids can do because they are afraid I might get hurt.

My parent/guardian encourages me to participate in activities.

My parent/guardian treats me in ways that make me feel bad about my behaviors.

My parent/guardian expects me to follow strict rules at home.

My parent/guardian punishes me no matter what I do.

My parent/guardian decides what I should wear or how I should look.

My parent/guardian is proud of me whenever I do something good. 
Submit or recommend next manuscript to SCIRP and we will provide best service for you:

Accepting pre-submission inquiries through Email, Facebook, LinkedIn, Twitter, etc. A wide selection of journals (inclusive of 9 subjects, more than 200 journals)

Providing 24-hour high-quality service

User-friendly online submission system

Fair and swift peer-review system

Efficient typesetting and proofreading procedure

Display of the result of downloads and visits, as well as the number of cited articles Maximum dissemination of your research work

Submit your manuscript at: http://papersubmission.scirp.org/

Or contact ce@scirp.org 